\title{
Mode of action of Lippia graveolens essential oil on Salmonellaenterica subsp. enterica serovar Typhimurium
}

\section{Annie Rubio Ortega}

Laboratory of Chemical Ecology, Agricultural Pest Group, National Center for Animal and Plant Health, San José de las Lajas, Mayabeque, Cuba https://orcid.org/0000-0001-8780-3081

\section{Elodie Guinoiseau}

CNRS UMR 6134 SPE, Université de Corse, BP 52, 20250 Corte, France

\section{Yann Quilichini}

CNRS UMR 6134 SPE, Université de Corse, BP 52, 20250 Corte, France

\section{Dominique de Rocca Serra}

CNRS UMR 6134 SPE, Université de Corse, BP 52, 20250 Corte, France

\section{Jean-Pierre Poli}

CNRS UMR 6134 SPE, Université de Corse, BP 52, 20250 Corte, France

\section{Maria del Carmen Travieso Novelles}

Laboratory of Chemical Ecology, Agricultural Pest Group, National Center for Animal and Plant Health, San José de las Lajas, Mayabeque, Cuba

\section{Ivette Espinosa Castaño}

Laboratory of Bacteriology, Microbiology Group, National Center for Animal and Plant Health, San José de las Lajas, Mayabeque, Cuba

\section{Oriela Pino Pérez}

Laboratory of Chemical Ecology, Agricultural Pest Group, National Center for Animal and Plant Health, San José de las Lajas, Mayabeque, Cuba

\section{Liliane Berti}

CNRS UMR 6134 SPE, Université de Corse, BP 52, 20250 Corte, France

\section{Vannina Lorenzi ( $\square$ lorenzi_v@univ-corse.fr)}

CNRS UMR 6134 SPE, Université de Corse, BP 52, 20250 Corte, France

\section{Research}

Keywords: Salmonella Typhimurium, Lippia graveolens essential oil, Foodborne bacteria, mode of action Posted Date: March 10th, 2021

DOl: https://doi.org/10.21203/rs.3.rs-245997/v1 
License: (c) (i) This work is licensed under a Creative Commons Attribution 4.0 International License. Read Full License 


\section{Abstract}

The essential oils are a powerful natural resource with antibacterial activity. This work aims at the mode of action of Lippia graveolens Kunth essential oil of plants growing in Cuba on Salmonella enterica subsp. enterica serovar Typhimurium. The effects of this oil on cell integrity were determined by time-kill, bacteriolysis and loss of 260 and 280-nm-absorbing material assays and total proteins leakage. Also, depolarization of the membrane by essential oil was monitored and intracellular and extracellular ATP was measured. The transmission electron microscopy (TEM) was used for observed morphologic change. Minimum inhibitory concentration (MIC) of L. graveolens essential oil and minimum bactericide concentration (MBC) were 0.4 and $0.8 \mathrm{mg} / \mathrm{mL}$ respectively. This essential oil showed a bactericidal action against over $\mathrm{S}$. Typhimurium in a few minutes. After treatment, the cell lysis was not occurred, but little intracellular material and total proteins leakage were observed. This essential oil depolarizes the cell membrane, disturb metabolic processes and changes the structure of cytoplasmic membrane. These results suggest as primary mode of action of $L$. graveolens essential oil over $S$. Typhimurium an increased permeability of the membrane and depolarization of inside membrane, inhibition of ATPase or disturbance in proton motive force that finally provokes death of cells. L. graveolens essential oil is a botanic resource can be used for the control of the salmonellosis, foodborne disease.

\section{Introduction}

Foodborne diseases have important repercussions on public health, food safety, productivity, and poverty. Every year, almost 600 million people get sick and 420,000 die from foodborne diseases, with a loss of 33 million of healthy life years. Low and middle-income countries are the most affected, with estimated annual costs of US $\$ 110$ billion in productivity losses, commercial losses and costs of treatment of diseases due to the consumption of unhealthy food (FAO, WHO, \& WTO, 2019). With the phenomenon of climate change, there has been a significant increase in the risk to public health, through its effects on microorganism. Besides, the influence of this phenomenon on antimicrobial resistance (RAM) and zoonotic diseases is known both directly related to food safety (WHO, 2019).

The genus Salmonella is among the main pathogens causing foodborne diseases worldwide (WHO, 2015). Salmonella is a zoonotic pathogen, a bacillus anaerobic facultative gram-negative bacteria, that belongs to the Enterobacteriaceae family (Jajere, 2019). There are more than 2,500 serovars of Salmonella enterica (Lamas et al., 2018), with a wide range of hosts that includes animals, human, and plants. It can be found in the intestines of many animals of economic and food importance, such as pigs and poultry (Ferrari et al., 2019). In plants, $S$. Typhimurium is not limited to the surface, it invades and reproduces in plant tissues, which makes common use practices, such as washing or sterilizing the surface of plants infected with Salmonella, not prevent infection in humans or animals (Chen et al., 2018; Schikora, Carreri, Charpentier, \& Hirt, 2008). This species can acquire antibiotic resistance and form biofilms (Cardoen et al., 2009; Doyle et al., 2016; Morganti et al., 2018), elements that include it in the WHO priority pathogen list for research and development of new antibiotics (Tacconelli et al., 2017). 
Essential oils are aromatic and volatile liquids, which have a complex composition and are obtained by different methods of extraction as hydrodistillation, steam distillation and cold-press techniques fom fresh and dry plant material, which includes flowers, roots, barks, leaves, seeds, husks, fruits, wood and whole plants (Aziz et al., 2018; Preedy, 2015). Essential oils stand out among natural products of plant origin for their versatility in biological properties. Antibacterial activity as broad-spectrum substances against Gram-positive and Gram-negative bacteria, including activity on antibiotic-resistant strains, is one of their main advantages (Guinoiseau et al., 2015; Leyva-López, Gutiérrez-Grijalva, Vazquez-Olivo, \& Heredia, 2017).

Plants of the Verbenaceae family are known by the capacity for essential oils production with diversity uses. The Lippia genus includes more than 100 species of plants, which have been used in traditional Latin American medicine (Almeida et al., 2018). One of the major commercial species is Lippia graveolens Kunth known as Mexican oregano, an aromatic plant native of Southern North America, it is used in folk medicine mainly in dermatological, gastrointestinal and respiratory affections (Preedy, 2015) and as culinary seasoning (Pascual, Slowing, Carretero, Sánchez Mata, \& Villar, 2001). The essential oil of this plant exhibits antibacterial activity against Gram-positive and Gram-negative bacteria, which is related to major components as thymol, carvacrol, p-cymene (Hernández et al., 2009).

Studies on the antimicrobial activity of essential oils are abundant throughout the world, however, in terms of understanding the mode of action of these natural products as antimicrobials, more depth is needed with an integrative vision. This article is aimed at the mode of action of the essential oil of $L$. graveolens of plants grown in Cuba on strain of Salmonella enterica subsp. enterica serovar Typhimurium.

\section{Materials And Methods}

\subsection{Essential Oil}

The essential oil of L. graveolens was supplied by the Chemical Ecology Laboratory of National Center of Planta and Animal Health of Cuba. The plant material was collected in the town of Jaruco, Mayabeque, Cuba, located at 23. 076573 and -81.964266 . The essential oil was obtained by the method of hydrodistillation for three hours, using a Clevenger equipment (Benachour, Ramdani, Lograda, Chalard, \& Figueredo, 2020). This essential oil was characterized and analyzed its chemical composition analyzed by GC-MS in previous work. The majority compounds include thymol (42.7\%), carvacrol $(22.2 \%)$, pcymene $(6.5 \%)$.

\subsection{Bacterial Strains and Growth Conditions}

Salmonella enterica subsp. enterica serovar Typhimurium ATCC 14028 (CIP 104115) strain was purchased from the Collection of Institute Pasteur (CIP, Paris, France). Before each experiment, the strain was routinely grown at $37^{\circ} \mathrm{C}$ on Mueller-Hinton 2 agar (MHA, Oxoid). 


\subsection{Antimicrobial susceptibility testing}

\subsubsection{Disc Diffusion Assays}

The agar diffusion method was used for the determination of antibacterial activities (CLSI, 2018). Inoculum were prepared by diluting overnight cultures in Mueller-Hinton broth (MHB, Oxoid) medium to approximately $10^{6} \mathrm{CFU} / \mathrm{mL}$. Filter paper discs ( $6 \mathrm{~mm}$ diameter, Dominique Dutscher) were placed onto the inoculated Petri dishes containing Mueller-Hinton 2 agar (MHA, Oxoid) and was applied $15 \mu \mathrm{L}$ of the tested products in the paper discs. After keeping at room temperature for $1 \mathrm{~h}$, plates were incubated at $37^{\circ} \mathrm{C}$ for $24 \mathrm{~h}$. Diameters of inhibition zones were measured $(\mathrm{mm})$ and recorded as the mean \pm standard deviation (SD). Each test was performed in triplicate on at least three separate experiments. Ciprofloxacin discs (5 $\mu$ g, Bio-Rad) was used as positive control.

\subsubsection{Minimum Inhibitory Concentration and Minimum Bactericidal Concentration Assays}

The minimum inhibitory concentration (MIC) assays were performed by a rapid INT ( $p$ iodonitroterazolium chloride, Sigma-Aldrich) colorimetric assay (Guinoiseau et al., 2015). The $L$. graveolens oil was serially twofold diluted in dimethylsulfoxide (DMSO, Sigma-Aldrich). The DMSO was previously tested for antibacterial activity and no detrimental effect on bacterial growth has been observed at the concentration used. The solutions obtained were then added $(10 \mu \mathrm{L})$ to a 96 -well microplate containing $190 \mu \mathrm{L}$ of MHB $(1: 20, \mathrm{v} / \mathrm{v})$ inoculated with $10^{6} \mathrm{CFU} / \mathrm{mL}$. The microplates were incubated at $37^{\circ} \mathrm{C}$ for $24 \mathrm{~h}$. The MICs of the samples were then detected following addition $(50 \mu \mathrm{L})$ of INT $(0.2 \mu \mathrm{g} / \mathrm{mL})$. Viable bacteria reduced the yellow dye to pink. The MIC is defined as the lowest sample concentration that prevents this change and results in the inhibition of bacterial growth. All determinations were performed in triplicate and a negative control, consisting of MHB with DMSO $(5 \%$, $\mathrm{v} / \mathrm{v}$ ), was systematically included. An inoculation loop was introduced in each well and seeded on a Muller Hinton agar plate, free of the antimicrobial agent to determine the minimum bactericidal concentration (MBC), which is defined as the lowest concentration of the oil that resulted in a negative subculture.

\subsection{Time-Kill Studies}

Time-kill procedure was performed according to the method described by Klepser et al (Klepser, Ernst, Lewis, Ernst, \& Pfaller, 1998) and modified by Viljoen et al. (Viljoen et al., 2003). The antibacterial activity of $L$. graveolens essential oil used at their MIC were evaluated against $S$. Typhimurium by measuring the reduction in the number of CFU (Colony Forming Units) per milliliter at 0, 15, 30, 45, 60, 120, 180, 240 minutes and $24 \mathrm{~h}$ of incubation at $37^{\circ} \mathrm{C}$ with agitation. The tested product was applied at MHB with DMSO $(0.1 \%)$ inoculated with $10^{6} \mathrm{CFU} / \mathrm{mL}$. The inoculated medium containing DMSO and without essential oil was used as control. At each evaluation time, aliquot of $100 \mu \mathrm{L}$ was taken and serially diluted in MHB; from each serial dilution step, $100 \mu \mathrm{L}$ were transferred to two MHA plates in numbered sections and incubated at $37^{\circ} \mathrm{C}$ for $24 \mathrm{~h}$. Colony-forming units were counted after incubation. This assay was performed in triplicate. 


\subsection{Cell Integrity Studies}

Bacteriolysis assay was carried out according to the standard method described by Carson et al. (Carson, Mee, \& Riley, 2002). A bacterial suspension was prepared by inoculating two colonies of $S$. Typhimurium from overnight cultures on MHA into $40 \mathrm{ml}$ of MHB, which was incubated at $37^{\circ} \mathrm{C}$ for $24 \mathrm{~h}$ with shaking. After incubation, the bacteria were separated from the growth medium by centrifugation at 10,472 rad/s for 12 min at $4^{\circ} \mathrm{C}$, washed twice with phosphate-buffered saline (PBS, pH 7.4) and resuspended in PBS supplemented with $0.01 \%$ Tween 80 (PBS-T, v/v). The bacterial suspension was adjusted so that the optical density (OD) at $550 \mathrm{~nm}$ of a 1 in 100 dilution was $0.310\left(\sim 3 \times 10^{8} \mathrm{CFU} / \mathrm{mL}\right)$. L. graveolens essential oil was added to the bacterial suspension at the MIC. PBS-T was added to the control suspension. The suspensions obtained were mixed for $20 \mathrm{~s}$ with a Vortex mixer. Samples $(1 \mathrm{~mL})$ were taken in duplicate every 30 minutes from $0 \mathrm{~h}$ to $2 \mathrm{~h}$. They were centrifuged and the pellet was resuspended in $1 \mathrm{~mL}$ of PBS-T. The optical density at $620 \mathrm{~nm}$ was measured immediately (Jasco UVisco UV-1200 spectrophotometer). This assay was performed on three independent experiments. The results were expressed as a ratio (in percent) of the OD620 at each time point versus the OD620 at 0 min.

\subsection{Loss of Cytoplasmic Material}

The release of 260-nm and 280-nm absorbing materials from $S$. Typhimurium cells treated with $L$. graveolens essential oil at MIC, was performed on the bacterial suspension $\left(10^{8} \mathrm{CFU} / \mathrm{mL}\right)$ in PBS supplemented with $0.01 \%$ Tween 80 (PBS-T, v/v). Suspension without essential oil was used as a control. The samples were incubated at $37^{\circ} \mathrm{C}$ with shaking. They were taken at time $0,30,60,90$ and $120 \mathrm{~min}$, and centrifuged at 10,472 rad/s for 12 minutes. The absorbance of the obtained supernatant was measured at 260 and $280 \mathrm{~nm}$ using a spectrophotometer (Jasco UVisco UV-1200). Each test was performed on three independent experiments. The results were expressed as a difference of the OD260 or OD280 at each time point versus the OD260 or OD280 at time 0.

\subsection{Determination of released proteins}

Total protein losses released by the action of the L. graveolens essential oil over $S$. Typhimurium were determined by Lowry's method (Lowry, Rosebrough, Farr, \& Randall, 1951). The preparation of the inoculum and the samples was performed equal to the loss of material. Also, $1 \%$ sodium lauryl sulfate (SDS) and bovine serum albumin (BSA) were used as a standard. After treatment with the MIC, the samples were taken at time 0 , and 120 minutes, and centrifuged at 10,472 rad/s for 12 minutes. Suspension without essential oil was used as negative control. Lowry's method was applied and the optical density was measured at $730 \mathrm{~nm}$ in the Jasco UVisco UV-1200 spectrophotometer. Each sample was prepared in triplicate and three independent experiments were performed. The results were expressed as mean \pm standard error.

\subsection{Measurement of Intra- and Extra-Cellular Adenosine 5'-Triphosphate (ATP) Concentrations}


To determine the action of $L$. graveolens essential oil on energetic molecules, the intracellular and extracellular ATP concentrations were measured as described by Gill and Holley (Gill \& Holley, 2006), with modifications of Turgis et al. (Turgis, Han, Caillet, \& Lacroix, 2009). The overnight cultures of $S$. Typhimurium were centrifuged for 10 minutes at $10,472 \mathrm{rad} / \mathrm{s}$ and the supernatants were removed. The cell pellets were washed two times with $20 \mathrm{mM}$ of phosphate potassium buffer (PPB, pH 7.0) and then cells were collected by centrifugation under the same conditions. A cell suspension $\left(10^{8} \mathrm{CFU} / \mathrm{mL}\right)$ was prepared in PPB $(20 \mathrm{mM} ; \mathrm{pH} 7.4)$ with glucose $(50 \mathrm{mM})$ and DMSO $(0,1 \%)$. The essential oil was applied at the MIC. $30 \mathrm{mM}$ of polymyxin B (PMB) was used as positive control and the suspension without essential oil as the negative control. The treatments were incubated at $37^{\circ} \mathrm{C}$ for 7 min with agitation. Then the samples were centrifuged at $10,472 \mathrm{rad} / \mathrm{s}$ for 12 minutes and the supernatant was separated from the pellet.

For ATP extra-cellular, the supernatants were put quickly in ice, and $50 \mu \mathrm{L}$ of the samples were added to 96 well black plate for duplicate. Then, $50 \mu \mathrm{L}$ of MIXED kit for ATP (ATP-kit, Sigma) was applied in each well, and the plate was incubated for $30 \mathrm{~min}$ in ice in darkness. Fluorescence was measured using FP83000 Jasco spectrofluorophotometer (excitation wavelength $\left(\lambda_{\mathrm{ex}}\right)=535 \mathrm{~nm}$ and excitation wavelength $\left(\lambda_{\mathrm{em}}\right)=587 \mathrm{~nm}$ ). Each test was performed on three independent experiments. The results were expressed as a ratio (in percent) of the relative fluorescence unit (RFU) at each time point versus the RFU of the DMSO control.

For ATP intra-cellular, the pellets were resuspended in $1 \mathrm{~mL}$ of $\mathrm{NaCl}(0,85 \%)$ and centrifugated at the same previous conditions. The cells were resuspended in $200 \mu \mathrm{L}$ of ATP buffer assays (ATP-kit, Sigma). After, $5 \mu \mathrm{L}$ of $15 \%$ ammonium bromide (CTAB, Sigma) were added in each treatment and incubated at room temperature for $15 \mathrm{~min}$. The samples were centrifuged and $50 \mu \mathrm{L}$ of the supernatant was taken and applied to 96 well black plate for duplicate. Then this experiment was continued like for ATP extra-cellular assay.

\subsection{Membrane depolarization assay}

The cytoplasmic membrane depolarization activity of L. graveolens essential oil over $S$. Typhimurium was measured by using 3,3'-dipropylthiadicarbocyanine iodide ( DiSC $_{3}$, Sigma) (Chehimi, Pons, Sablé, Hajlaoui, \& Limam, 2010). A S. Typhimurium overnight culture in MHB was centrifuged at 10,472 rad/s for 12 minutes at $4^{\circ} \mathrm{C}$, washed twice with phosphate-buffered saline (PBS, $\mathrm{pH} 7.4$ ), and resuspended in buffer solution (10 mM HEPES (4-(2-hydroxyethyl)-1-piperazineethanesulfonic acid) with glucose $50 \mathrm{mM}$ at $\mathrm{pH} 7.0$, and DMSO $0.1 \%$ ). The bacterial suspension was adjusted at $10^{8} \mathrm{CFU} / \mathrm{mL}$ and $99 \mu \mathrm{L}$ was applied to 96 well black plate for duplicate. The cells were incubated with $1.68 \mu \mathrm{M} \mathrm{DiSC}_{3}$ at room temperature with shaking for $1 \mathrm{~h}$. Then $\mathrm{KCl}$ was added to a final concentration of $0.1 \mathrm{M}$ to equilibrate the cytoplasmic and external $\mathrm{K}^{+}$and incubated for $5 \mathrm{~min}$. An aliquot of $1 \mu \mathrm{L}$ of $L$. graveolens essential oil was applied at MIC and, as positive controls, $30 \mathrm{mM}$ of polymyxin B (PMB) and $4 \mathrm{mM}$ CTAB. Suspension without essential oil was used as the negative control. Fluorescence was monitored with an FP-83000 Jasco spectrofluorophotometer (excitation wavelength $\left(\lambda_{\mathrm{ex}}\right)=622 \mathrm{~nm}$ and excitation wavelength $\left(\lambda_{\mathrm{em}}\right)=$ 
$670 \mathrm{~nm}$ ). The results were expressed at relative fluorescence unit (RFU). This assay was performed on three independent experiments.

\subsection{Transmission Electron Microscopy (TEM)}

A suspension of $S$. Typhimurium in the exponential phase of growth was prepared by inoculating then incubating $80 \mathrm{~mL}$ of $\mathrm{MHB}$ at $37^{\circ} \mathrm{C}$ for $24 \mathrm{~h}$ with shaking. The bacterial suspension was adjusted so that the optical density at $620 \mathrm{~nm}$ (OD620) of a 1 in 100 dilution in MHB was $0.200\left(10^{8} \mathrm{CFU} / \mathrm{mL}\right)$ with Tween $80(0.1 \%, v / v)$. The cells of $S$. Typhimurium were treated with the MIC of L. graveolens essential oil for 7 $\mathrm{min}$. The negative control was the suspension without essential oil. After centrifugation at 10,472 rad/s for 10 minutes, the pellets were first fixed in $2.5 \%$ glutaraldehyde in $0.1 \mathrm{M}$ cacodylate buffer $(\mathrm{pH} 7.2)$ for 1 $\mathrm{h}$ at room temperature and then post-fixed in $2 \%$ osmium tetroxide in $0.1 \mathrm{M}$ cacodylate buffer $(\mathrm{pH} 7.2)$ for $1 \mathrm{~h}$ at room temperature. The postfixed microbial pellets were processed in graded ethyl alcohol, propylene oxide, Spurr resin and cured for $24 \mathrm{~h}$ at $45^{\circ} \mathrm{C}$. Ultrathin sections were stained with uranyl acetate followed by lead citrate and then examined with a transmission electron microscope (HITACHI H$7650)$ at an accelerating voltage of $80 \mathrm{kV}$.

\section{Results}

\subsection{Susceptibility of Salmonella Typhimurium to Lippia graveolens essential oil}

The antibacterial activity of $L$. graveolens essential oil over $S$. Typhimurium strain is presented in Table 1 . A great zone of inhibition was revealed by the action of this essential oil and It is correspondence with a strong inhibition zone (> $20.1 \mathrm{~mm}$ ) (Mazzarrino et al., 2015). The results amount the essential oils and the antibiotic control showed significant differences, with larger value for the natural product. The MIC value was $0.4 \mathrm{mg} / \mathrm{mL}$ and double value of MIC was the MBC.

Table 1. Inhibition zone, Minimal Inhibitory Concentration (MIC) and Minimum Bactericidal Concentration (MBC) of Lippia graveolens essential oil on S. Typhimurium strain.

\begin{tabular}{llll}
\hline Treatments & $\begin{array}{l}\text { Inhibition zone } \\
(\mathrm{mm}) \pm \mathrm{STD}\end{array}$ & $\begin{array}{l}\text { MIC } \\
(\mathrm{mg} / \mathrm{mL})\end{array}$ & $\begin{array}{l}\text { MBC } \\
(\mathrm{mg} / \mathrm{mL})\end{array}$ \\
\hline L. graveolens essential oil & $56.67 \pm 3.33^{\mathrm{a}}$ & 0.4 & 0.8 \\
\hline Ciprofloxacin & $32.57 \pm 0.33^{\mathrm{b}}$ & - & - \\
\hline
\end{tabular}

Mean values \pm standard deviation, in a column that are not followed by the same letter are significantly different $(\mathrm{p}<0.05)$.

\subsection{Time-Kill Studies}

The effect of $L$. graveolens essential oil on the growth of $S$. Typhimurium demonstrated a negative kinetic with reduced viability at MIC (Fig. 1). This essential oil had a bactericidal end-point $(99.9 \%$ or $\geq 2 \log 10$ 
of inhibition) in only 15 minutes of treatment, time that was taken into account for the remainder of the experiments. The total inhibition was at $2 \mathrm{~h}$ of treatment and was remained for $24 \mathrm{~h}$ (data not shown). The control grew up in the time.

\subsection{Cell Integrity Studies}

The cells of $S$. Typhimurium not showed a change in OD at $620 \mathrm{~nm}$ after $2 \mathrm{~h}$ of treatment with $L$. graveolens essential oil at MIC (Figure 2). In all times, the samples had more than $80 \%$ of cells integrity indicating that cell lysis did not occur.

\subsection{Loss of Cytoplasmic Material}

The L. graveolens essential oil at MIC induced the releasing of 260-nm and $280-\mathrm{nm}$ absorbing materials from S. Typhimurium (Figure 3). The loss of absorbent material at both 260 and $280 \mathrm{~nm}$ was observed significantly $(p<0.05)$ after $60 \mathrm{~min}$ of exposure to the oil. The maximum proportion obtained at $2 \mathrm{~h}$ of treatment; however, was less than $20 \%$.

\subsection{Determination of released proteins}

To corroborate the release of cellular components by the action of essential oil, total proteins were determined. This test was carried out at time 0 and $2 \mathrm{~h}$, time of maximum release of cellular content demonstrated in the cytoplasmic material loss test. No significant changes were shown between oil treatment and the control at the time of exposure. Nevertheless, the results of total proteins leakage of $S$. Typhimurium for the action of the essential oil $(0,35 \pm 0,27 \mathrm{mg} / \mathrm{mL})$ revealed larger concentration than the control $(0,04 \pm 0,02 \mathrm{mg} / \mathrm{mL})(p<0.05)$.

\subsection{Membrane depolarization assay}

After treatment with $L$. graveolens essential oil, $S$. Typhimurium cells have disturbances in the membrane (Figure.4). The change of value of the membrane potential was similar to the positive control, polymyxin B, which is known to induce the formation of pores in the membrane (Poirel, Jayol, \& Nordmanna, 2017).

\subsection{Measurement of Intra- and Extra-Cellular Adenosine 5'-Triphosphate (ATP) Concentration}

Measurements of ATP intracellular and extracellular were determined in S. Typhimurium cells after 7 minutes treatment with L. graveolens essential oil at MIC (Figure 5). Intracellular ATP was reduced significantly $(p<0.05)$ by the essential oil $(7.8 \%$ of RFU), in the same way as the antibiotic polymyxin $B$ ( $8.6 \%$ of RFU). The concentration of extracellular ATP was very low (less than $10 \%$ of RFU) whatever the treatment but the highest value was observed in presence of the essential oil.

\subsection{Transmission Electron Microscopy (TEM)}

The essential oil effect over S. Typhimurium was observed by transmission electron microscopy (Figure 6). L. graveolens affected the cellular integrity of Salmonella cells after only 7 minutes of exposure. The 
majority of cells conserved the external morphology. However, these cells presented a longer distance between the outside and plasmic membrane, which was observed as more periplasmic space. The plasmic material was conserved inside of the plasmic membrane, but a change in density was observed. The cells untreated were observed with the typical structure of gram-negative.

\section{Discussion}

The Lippia graveolens essential oil of plants cultivated in Cuba is a natural product with a phenolic group as majority compounds for $64 \%$ of total. Thymol, carvacrol and $p$-cimene have been reported as majoritarian compounds of essential oil of L. graveolens cultivated in Mexico (thymol $10.43 \%$, carvacrol $43.7 \%, p$-cimene 6,4) (Preedy, 2015) and Rio de la Virgen- Jutiapa in Guatemala (carvacrol $44.8 \%, p$ cimene $21.8 \%$, thymol 7.4\%) (Salgueiro, Cavaleiro, Gonçalves, \& Proença Da Cunha, 2003), but the Cuban cultivar has more quantities of this structurestogether. This composition assures a powerful activity over Salmonella Typhimurium. Results from disc diffusion assay and MIC $(0.4 \mathrm{mg} / \mathrm{mL})$ and $\mathrm{MBC}(0.8 \mathrm{mg} / \mathrm{mL})$ values illustrated that it has a strong and consistent inhibitory effect against this foodborne pathogen.

Irreversible damage at viability cellular was confirmed in a short time (15 minutes) of treatment. Similar results were obtained by Kumar and Chul in 2014, using thymol over this strain (Chauhan \& Kang, 2014). Thymol at $0.750 \mathrm{mg} / \mathrm{mL}$ reduced the number of cells after $20 \mathrm{~min}$ of exposition. The membrane cellular is vital to cell structure, because it intervenes in many processes such as energy conversion, nutrient processing, synthesis of structural macromolecules and secretion of growth regulators (Swamy, Sayeed Akhtar, Sinniah, Akhtar, \& Sinniah, 2016). For this, plasmic membrane is considerate as an important site of action, and indeed, many essential oil constituents as thymol and carvacrol, have been described to possess activity on this particular structure (Hyldgaard, Mygind, \& Meyer, 2012).

The hydrophobic nature of essential oils can interact with the lipid membrane of bacterial pathogens, resulting in the leakage of the inner cell components, damage in potassium ion reflux, and finally leading to cell death (Saad, Muller, \& Lobstein, 2013). Membrane disrupts, affecting the structural stability of the membrane or change in the permeability are principal modifications over the membrane for action of essential oil (Hyldgaard et al., 2012). Generally, phenolic compounds are responsible of major bactericide effect against food-borne pathogenic bacteria. The phenolic compounds disrupt the cell membrane as well as effectively inhibit the functional properties of the cell, and eventually leaking the inner materials of the cell (Bajpai, Baek, \& Kang, 2012).

However, L. graveolens essential oil did not induce abrupt cell lysis on $S$. Typhimurium within two hours of treatment, and was coherent with the outflow of little absorbent cytoplasmic matrix at $260 \mathrm{~nm}$ and 280 $\mathrm{nm}$. The total proteins released showed a slow change in the permeability membrane. These results suggest that the initial action is not the total destruction of the membrane. Conversely, thymol severely disrupted the membrane of $S$. Typhimurium, resulting in the release of intracellular components such as deoxyribonucleic acid (DNA) in the cell supernatant (Chauhan \& Kang, 2014). These differences in results 
are consistent with the research approach in which has been worked and highlights the need to study the mode of action of essential oils as an integral product and not focus on the study of an only component.

On the other hand, effects in the cellular activity were monitored by messing the intracellular and extracellular ATP concentrations. Indeed, in cells treated with L. graveolens no ATPin, was detected. This drastic decrease is not correlated to the release of ATP in the extracellular medium. The depletion of the internal ATP pool was associated with a change in membrane potential. These results were similar to those demonstrated by Ultee et al in 2002 (Ultee, Bennik, \& Moezelaar, 2002). More, those results are also associated to change in membrane potential. So, L. graveolens essential oil, like as carvacrol, does not enhance the membrane permeability for ATP and the depletion of the internal ATP pool results suggest the reduction of ATP synthesis and/or increase ATP hydrolysis. Also, this depletion of the ATP pool following the addition of lipophilic components was observed in other studies. The alcohol fraction extracts of Cistus ladaniferus essential oil have the capacity to vanish the ATPin on Staphylococcus aureus cells, without growing the ATP out (Guinoiseau et al., 2015). More, components like carvacrol, eugenol and cinnamaldehyde inhibit the ATPase activity of Escherichia coliand Listeria monocytogenes (Gill \& Holley, 2006).

Adenosine triphosphate (ATP) is used in vital cell processes that require energy as respiration, survival, growth and replication. Other functions of ATP include signaling function, participation in storing and supplying energy in metabolism and enzymatic reactions. In Salmonella, is known that ATP regulate virulence gene mgtC (Mempin et al., 2013). Cellular respiration depends on the respiratory chain in the plasma membrane. This converts redox energy into an electrochemical gradient of protons (protonmotive force) which subsequently drives ATP formation from ADP and phosphate by ATP synthase. The membrane potential and the transmembrane proton gradient are the two parameters of respiratory chain in the plasma membrane. Nevertheless, ATP synthase in bacteria is dependent on the potential component (Dimroth, Kaim, \& Matthey, 2000). So, L. graveolens essential oil change the potential of membrane of $S$. Typhimurium and it can affect the ATP synthase, with damage in the respiratory chain of cellular respiration.

TEM was used to observe the effects of $L$. graveolens essential oil inside of de $S$. Typhimurium cells. Outwardly, the cell remains morphologically intact changes occur inside of the bacteria: (i) outside membrane separates from the plasmic membrane; (ii) differences in the electron-dense structure of cytoplasmic material. This phenomenon can be related to the capacity of essential oil diffuse, penetrate and disorganize the lipid tail region of the membrane (Stevens, 2004). The total volume of the membrane is roughly constant, but membrane thinning results in lateral expansion, affecting the mechanical properties of the membrane. As the area per lipid grows the surface tension increases and the bending modulus decreases dramatically, implying membrane deformation (Stevens, 2004).

The expansion of the membrane also results in a reduction in the packing of the lipid molecules leading to the formation of a large number of cavities, significantly reducing the translocation free energy of water molecules across the lipid tail region. As a result, a large number of water translocations occur, and 
the membrane becomes leaky with the colleapse of the transmembrane potential and additional membrane dysfunction, such as inhibition of ATP production and loss of proton motive force and rapid death of the bacterium (Dimroth et al., 2000; Li et al., 2017).

Diverse researches have already highlighted changes in the morphology external of Salmonella strains by the action of essential oils. Raybaudi-Massilia et al. (Raybaudi-Massilia, Mosqueda-Melgar, \& MartínBelloso, 2006) described damages to the cellular membrane of Salmonella Enteritidis by action of lemongrass essential oil at $5 \mu \mathrm{L} / \mathrm{mL}$ in $24 \mathrm{~h}$, including its disruption of the same and leakage of cell content. Zataria multiflora Boiss. essential oil at $0.3 \mu \mathrm{g} / \mathrm{mL}$ in $1 \mathrm{~h}$ trigger important morphological damages in Salmonella Typhimurium, such as the increase permeabilization and disruption of membranes which allowed to the dye and the contents of the cells appeared depleted and amorphous (Moosavy et al., 2008). Also, cinnamaldehyde at $0.4 \%$ in one hour of treatment causes severe damage in Salmonella MT 2195 (Yossa et al., 2014).

Studies on antimicrobial activity of essential oils are abundant worldwide. However, the subject of the mode of action of these natural products as antimicrobials needs more depth (Carson et al., 2002), and an integral comprehension. This work shows a mode of action of $L$ graveolens essential oil on S. typhimurium, as antimicrobial alternative with an action over the membrane plasmatic and the metabolic process. Lipophilic and proteins studies can be realized in the future researches, for understand the molecular specific change in the membrane after treatment with the essential oil. Also, the action over metabolic process can be better comprehend with studies over particular enzymes, transcriptome, proteome or production of toxins.

The mechanisms of action are key to avoid antimicrobial resistance to antimicrobials. These studies create the basis for preventing the use of compounds with the same mode of action. The complexity of the chemical composition of essential oils allows different antimicrobial mode of action not only at a particular location but also at different cell sites. Synthetic antibiotic only has one mechanism of action over one target site: cell-wall biosynthesis, protein synthesis (subunit 30S or 50 S of ribosome), DNA replication and repair (RNA polymerase, DNA gyrase), folic acid metabolism, membrane structure or Lipid A biosynthesis. Therefore, there is a reemerging interest on essential oils as antibiotic alternative.

\section{Conclusion}

This work shows a natural option for treatment Salmonella strains, without risk of antimicrobial resistance. Lippia graveolens essential oil increases permeability of the membrane, disturb the inside membrane, metabolic energy depletionand finally provokes the death of cells in a few minutes. These results suggest the action of the essential oil on the cell membrane and over metabolic energetic process. In depth studies are need to fully understand if another structure or specific metabolic pathway have been damaged by this essential oil. Lippia graveolens essential oil is a resource with several modes of action as antibacterial with possibility for the preservation of food safety. 


\section{Abbreviations}

ATP: adenosine triphosphate; BSA: bovine serum albumin; CFU: Colony Forming Units; CTAB: ammonium bromide; DiSC $_{3}$ : 3,3'-dipropylthiadicarbocyanine iodide; DMSO: dimethylsulfoxide; DNA: deoxyribonucleic acid; HEPES: 4-(2-hydroxyethyl)-1-piperazineethanesulfonic acid; INT: $p$-iodonitroterazolium chloride; MBC: minimum bactericide concentration; MIC: minimum inhibitory concentration; MHA: Mueller-Hinton 2 agar; MHB: Mueller-Hinton broth; OD: optical density; PBS: phosphate-buffered saline; PBS-T: PBS supplemented with $0.01 \%$ Tween 80 ; PMB: polymyxin B; PPB: phosphate potassium buffer; RFU: relative fluorescence unit; SDS: sodium lauryl sulfate; TEM: transmission electron microscopy.

\section{Declarations}

\section{Acknowledgements}

The authors are grateful to the to the Collectivite territoriale de Corse for partial financial support. Also, this research was supported by Cooperation and cultural service of the French embassy in Cuba, within the framework of the project "Mode of action of essential oils on nosocomial and phytopathogenic bacteria", and mobility assistance to doctoral students; in especially we are grateful to the department of Scientific and University Cooperation of the French embassy in Cuba.

\section{Authors' contributions}

Annie Rubio- Ortega: designed and performed the experiments, processing of primary data, statistical analysis, prepared figures and/or tables, written the document. Elodie Guinoiseau: designed and performed the experiments, interpretation and integration of results. Yann Quilichini: designed and performed the experiments, review \& editing. Dominique de Rocca Serra: supervision, interpretation and integration of results, review \& editing. Jean-Pierre Poli: performed the experiments, processing of primary data and statistical analysis. Maria del Carmen Travieso- Novelles: supervision and interpretation and integration of results. Ivette Espinosa- Castaño: designed and performed the experiments and supervision, Oriela Pino- Pérez: interpretation and integration of results, review \& editing and funding acquisition. Liliane Berti: review \& editing, project administration and funding acquisition. Vannina Lorenzi: designed and performed the experiments, interpretation and integration of results, review \& editing, project administration and funding acquisition. All authors read and approved the final manuscript.

\section{Funding}

These results were supported by the Collectivité territoriale de Corse and the Cooperation and Cultural Service of the French embassy in Cuba.

\section{Availability of data and materials}

All data generated or analyzed during this study are included in this article. 


\section{Ethics approval and consent to participate}

All authors have read and agreed to the ethics for publishing the manuscript.

\section{Consent for publication}

All authors approved the consent for publishing the manuscript to the Journal of Bioresources and Bioprocessing.

\section{Competing interest}

There are no conflicts of interest to be declared.

\section{References}

Almeida, M. C., Pina, E. S., Hernandes, C., Zingaretti, S. M., Taleb-Contini, S. H., Salimena, F. R. G., ... Bertoni, B. W. (2018). Genetic diversity and chemical variability of Lippia spp. (Verbenaceae). BMC Research Notes, 11(1), 725. https://doi.org/10.1186/s13104-018-3839-y

Aziz, Z. A. A., Ahmad, A., Setapar, S. H. M., Karakucuk, A., Azim, M. M., Lokhat, D., ... Ashraf, G. M. (2018). Essential oils: extraction techniques, pharmaceutical and therapeutic potential - a review. Current Drug Metabolism, 19(13), 1100-1110. https://doi.org/10.2174/1389200219666180723144850

Bajpai, V. K., Baek, K. H., \& Kang, S. C. (2012). Control of Salmonella in foods by using essential oils: A review. Food Research International, Vol. 45, pp. 722-734. https://doi.org/10.1016/j.foodres.2011.04.052

Benachour, H., Ramdani, M., Lograda, T., Chalard, P., \& Figueredo, G. (2020). Chemical composition and antibacterial activities of Capparis spinosa essential oils from Algeria. Biodiversitas, 21(1), 161-169. https://doi.org/10.13057/biodiv/d210121

Cardoen, S., Van Huffel, X., Berkvens, D., Quoilin, S., Ducoffre, G., Saegerman, C., ... Dierick, K. (2009). Evidence-based semiquantitative methodology for prioritization of foodborne zoonoses. Foodborne Pathogens and Disease, 6(9), 1083-1096. https://doi.org/10.1089/fpd.2009.0291

Carson, C. F., Mee, B. J., \& Riley, T. V. (2002). Mechanism of action of Melaleuca alternifolia (tea tree) oil on Staphylococcus aureus determined by time-kill, lysis, leakage, and salt tolerance assays and electron microscopy. Antimicrobial Agents and Chemotherapy, 46(6), 1914-1920.

https://doi.org/10.1128/AAC.46.6.1914-1920.2002

Chauhan, A. K., \& Kang, S. C. (2014). Thymol disrupts the membrane integrity of Salmonella serovar Typhimurium in vitro and recovers infected macrophages from oxidative stress in an ex vivo model. Research in Microbiology, 165(7), 559-565. https://doi.org/10.1016/j.resmic.2014.07.001 
Chehimi, S., Pons, A. M., Sablé, S., Hajlaoui, M. R., \& Limam, F. (2010). Mode of action of thuricin S, a new class Ild bacteriocin from Bacillus thuringiensis. Canadian Journal of Microbiology, 56(2), 162-167. https://doi.org/10.1139/W09-125

Chen, Y., Pouillot, R., Santillana Farakos, S. M., Duret, S., Spungen, J., Fu, T. J., ... Van Doren, J. M. (2018). Risk assessment of salmonellosis from consumption of alfalfa sprouts and evaluation of the public health impact of sprout seed treatment and spent irrigation water testing. Risk Analysis, 38(8), 17381757. https://doi.org/10.1111/risa.12964

CLSI. (2018). Performance standards for antimicrobial disk susceptibility tests. Clinical and Laboratory Standards Institute, 13th ed. CLSI stand M02, Wayne, PA: USA.

Dimroth, P., Kaim, G., \& Matthey, U. (2000). Crucial role of the membrane potential for ATP synthesis by F1F0 ATP synthases. The Journal of Experimental Biology, 203, 51-59.

Doyle, M., Acheson, D., Newland, J., Dwelle, T., Flynn, W., Scott, H. M., ... Flood, T. (2016). Enhancing practitioner knowledge about antibiotic resistance: connecting human and animal health. Food Protection Trends, 36, 390-394.

FAO, WHO, \& WTO. (2019). International Forum on Food Safety and Trade. Geneva, Switzerland.

Ferrari, R. G., Rosario, D. K. A., Cunha-Neto, A., Mano, S. B., Figueiredo, E. E. S., \& Conte-Juniora, C. A. (2019). Worldwide epidemiology of Salmonella serovars in animal-based foods: A meta-analysis. Applied and Environmental Microbiology, 85(14). https://doi.org/10.1128/AEM.00591-19

Gill, A. O., \& Holley, R. A. (2006). Inhibition of membrane bound ATPases of Escherichia coli and Listeria monocytogenes by plant oil aromatics. International Journal of Food Microbiology, 111(2), 170-174. https://doi.org/10.1016/j.jfoodmicro.2006.04.046

Guinoiseau, E., Luciani, A., De Rocca Serra, D., Quilichini, Y., Berti, L., Lorenzi, V., \& Guinoiseau, E. (2015). Primary mode of action of Cistus ladaniferus $\mathrm{L}$. essential oil active fractions on Staphylococcus aureus strain. Advances in Microbiology, 5(5), 881-890. https://doi.org/10.4236/aim.2015.513092

Hernández, T., Canales, M., Avila, J. G., Garcia, A. M., Meraz, S., Caballero, J., \& Lira, R. (2009). Composition and antibacterial activity of essential oil of Lippia graveolens H.B.K. (Verbenaceae). Boletín Latinoamericano y Del Caribe de Plantas Medicinales y Aromáticas, 8(84), 295-300.

https://doi.org/http://www.redalyc.org/articulo.oa?id=85611265010

Hyldgaard, M., Mygind, T., \& Meyer, R. L. (2012). Essential oils in food preservation: mode of action, synergies, and interactions with food matrix components. Frontiers in Microbiology, 3(JAN). https://doi.org/10.3389/fmicb.2012.00012

Jajere, S. M. (2019). A review of Salmonella enterica with particular focus on the pathogenicity and virulence factors, host specificity and adaptation and antimicrobial resistance including multidrug 
resistance. Veterinary World, 12(4), 504-521. https://doi.org/10.14202/vetworld.2019.504-521

Klepser, M. E., Ernst, E. J., Lewis, R. E., Ernst, M. E., \& Pfaller, M. A. (1998). Influence of test conditions on antifungal time-kill curve results: Proposal for standardized methods. Antimicrobial Agents and Chemotherapy, 42(5), 1207-1212.

Lamas, A., Miranda, J. M., Regal, P., Vázquez, B., Franco, C. M., \& Cepeda, A. (2018). A comprehensive review of non-enterica subspecies of Salmonella enterica. Microbiological Research, 206, 60-73. https://doi.org/10.1016/j.micres.2017.09.010

Leyva-López, N., Gutiérrez-Grijalva, E., Vazquez-Olivo, G., \& Heredia, J. (2017). Essential oils of oregano: biological activity beyond their antimicrobial properties. Molecules, 22(6), 989. https://doi.org/10.3390/molecules22060989

Li, J., Koh, J. J., Liu, S., Lakshminarayanan, R., Verma, C. S., \& Beuerman, R. W. (2017, February 14). Membrane active antimicrobial peptides: Translating mechanistic insights to design. Frontiers in Neuroscience, Vol. 11, p. 73. https://doi.org/10.3389/fnins.2017.00073

Lowry, O. H., Rosebrough, N. J., Farr, A. L., \& Randall, R. J. (1951). Protein measurement with the Folin phenol reagent. Journal of Biological Chemistry, 193(1), 265-275.

Mazzarrino, G., Paparella, A., Chaves-López, C., Faberi, A., Sergi, M., Sigismondi, C., ... Serio, A. (2015). Salmonella enterica and Listeria monocytogenes inactivation dynamics after treatment with selected essential oils. Food Control, 50, 794-803. https://doi.org/10.1016/j.foodcont.2014.10.029

Mempin, R., Tran, H., Chen, C., Gong, H., Kim Ho, K., \& Lu, S. (2013). Release of extracellular ATP by bacteria during growth. BMC Microbiology, 13(1), 301. https://doi.org/10.1186/1471-2180-13-301

Moosavy, M.-H., Basti, A. A., Misaghi, A., Salehi, T. Z., Abbasifar, R., Mousavi, H. A. E., ... Noori, N. (2008). Effect of Zataria multiflora Boiss. essential oil and nisin on Salmonella typhimurium and Staphylococcus aureus in a food model system and on the bacterial cell membranes. Food Research International, 41(10), 1050-1057.

Morganti, M., Bolzoni, L., Pongolini, S., Scaltriti, E., Casadei, G., Carra, E., ... Delledonne, M. (2018). Rise and fall of outbreak-specific clone inside endemic pulsotype of Salmonella 4,[5],12:i:-; insights from highresolution molecular surveillance in Emilia-Romagna, Italy, 2012 to 2015. Eurosurveillance, Special ed, 42-52.

Pascual, M. E., Slowing, K., Carretero, E., Sánchez Mata, D., \& Villar, A. (2001). Lippia: Traditional uses, chemistry and pharmacology: A review. Journal of Ethnopharmacology, 76(3), 201-214. https://doi.org/10.1016/S0378-8741(01)00234-3

Poirel, L., Jayol, A., \& Nordmanna, P. (2017). Polymyxins: Antibacterial activity, susceptibility testing, and resistance mechanisms encoded by plasmids or chromosomes. Clinical Microbiology Reviews, 30(2), 
$557-596$.

Preedy, V. R. (2015). Essential oils in food preservation, flavor and safety (1st ed.; V. R. Preedy, Ed.). London, UK: Academic Press.

Raybaudi-Massilia, R. M., Mosqueda-Melgar, J., \& Martín-Belloso, O. (2006). Antimicrobial activity of essential oils on Salmonella Enteritidis, Escherichia coli, and Listeria innocua in Fruit Juices. In Journal of Food Protection (Vol. 69).

Saad, N. Y., Muller, C. D., \& Lobstein, A. (2013). Major bioactivities and mechanism of action of essential oils and their components. Flavour and Fragrance Journal. https://doi.org/10.1002/ffj.3165

Salgueiro, L. R., Cavaleiro, C., Gonçalves, M. J., \& Proença Da Cunha, A. (2003). Antimicrobial activity and chemical composition of the essential oil of Lippia graveolens from Guatemala. Planta Medica, 69(1), 80-83. https://doi.org/10.1055/s-2003-37032

Schikora, A., Carreri, A., Charpentier, E., \& Hirt, H. (2008). The dark side of the salad: Salmonella Typhimurium overcomes the innate immune response of arabidopsis thaliana and shows an endopathogenic lifestyle. PLOS ONE, 3(5). https://doi.org/10.1371/journal.pone.0002279

Stevens, M. J. (2004). Coarse-grained simulations of lipid bilayers. Journal of Chemical Physics, 121(23), 11942-11948. https://doi.org/10.1063/1.1814058

Swamy, M. K., Sayeed Akhtar, M., Sinniah, U. R., Akhtar, M. S., \& Sinniah, U. R. (2016). Antimicrobial properties of plant essential oils against human pathogens and their mode of action: an updated review. Evidence-Based Complementary and Alternative Medicine, 1-21. https://doi.org/10.1155/2016/3012462

Tacconelli, E., Carrara, E., Savoldi, A., Harbarth, S., Mendelson, M., Monnet, D. L., ... Zorzet, A. (2017). Discovery, research, and development of new antibiotics: the WHO priority list of antibiotic-resistant bacteria and tuberculosis. The Lancet Infectious Diseases, 18(3), 318-327.

https://doi.org/10.1016/S1473-3099(17)30753-3

Turgis, M., Han, J., Caillet, S., \& Lacroix, M. (2009). Antimicrobial activity of mustard essential oil against Escherichia coli 0157:H7 and Salmonella Typhi. Food Control, 20(12), 1073-1079.

https://doi.org/10.1016/j.foodcont.2009.02.001

Ultee, A., Bennik, M. H. J. J., \& Moezelaar, R. (2002). The phenolic hydroxyl group of carvacrol is essential for action against the food-borne pathogen Bacillus cereus. Applied and Environmental Microbiology, 68(4), 1561-1568. https://doi.org/10.1128/AEM.68.4.1561-1568.2002

Viljoen, A., Van Vuuren, S., Ernst, E., Klepser, M., Ba, serba, ser, H., Van Wyk, B.-E. E., ... Van Wyk, B.-E. E. (2003). Osmitopsis asteriscoides (Asteraceae)-the antimicrobial activity and essential oil composition of a Cape-Dutch remedy. Journal of Ethnopharmacology, 88(2-3), 137-143.

https://doi.org/10.1016/S0378-8741(03)00191-0

Page $17 / 22$ 
WHO. (2015). WHO estimates of the global burden of foodborne diseases.

https://doi.org/10.1080/08897070209511505

WHO. (2019). Food safety, climate change and the role of WHO. In Food and Chemical Toxicology. https://doi.org/10.1016/j.fct.2009.02.005

Yossa, N., Patel, J., Macarisin, D., Millner, P., Murphy, C., Bauchan, G., \& Lo, Y. M. (2014). Antibacterial activity of cinnamaldehyde and sporan against Escherichia coli 0157:H7 and Salmonella. Journal of Food Processing and Preservation, 38(3), 749-757. https://doi.org/10.1111/jfpp.12026

\section{Figures}

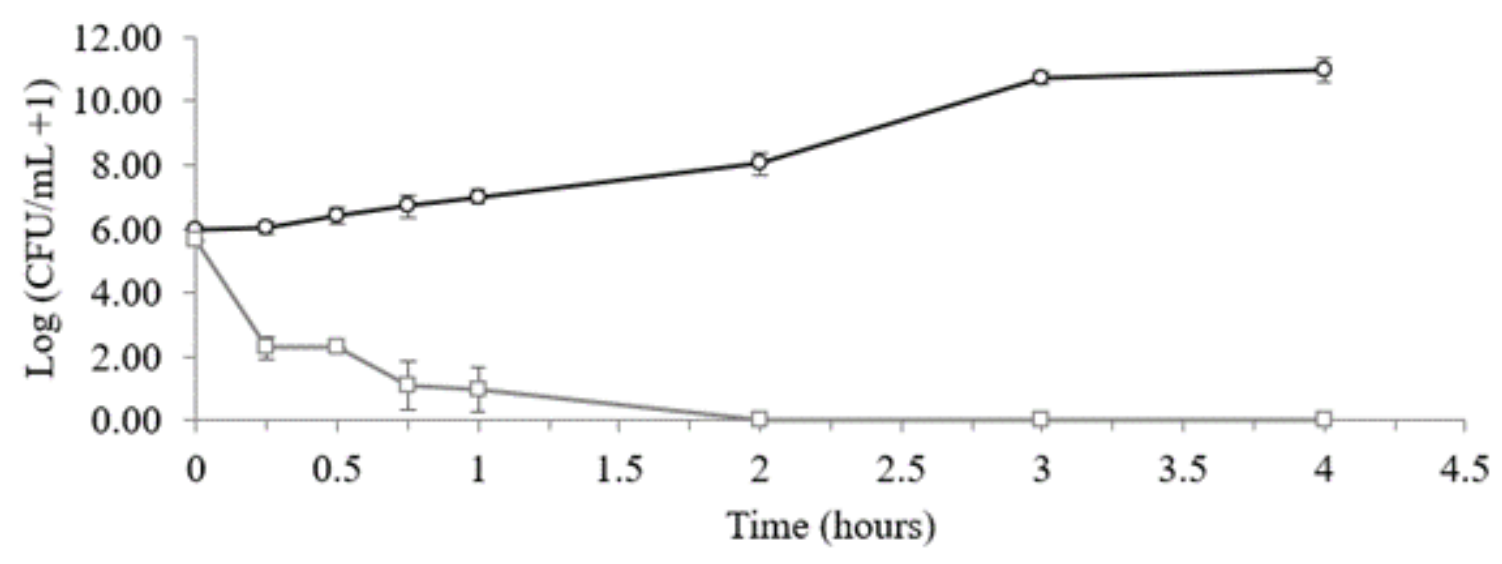

$\multimap$ Control $\quad \rightarrow-L$. graveolens $(0,5 \mathrm{mg} / \mathrm{mL})$

\section{Figure 1}

Time-kill curves of S. Typhimurium treated with Lippia graveolens essential oil (squares) at MIC and untreated cultures (circles). Mean values of triplicate independent experiments and standard deviation are shown $(n=6)$.

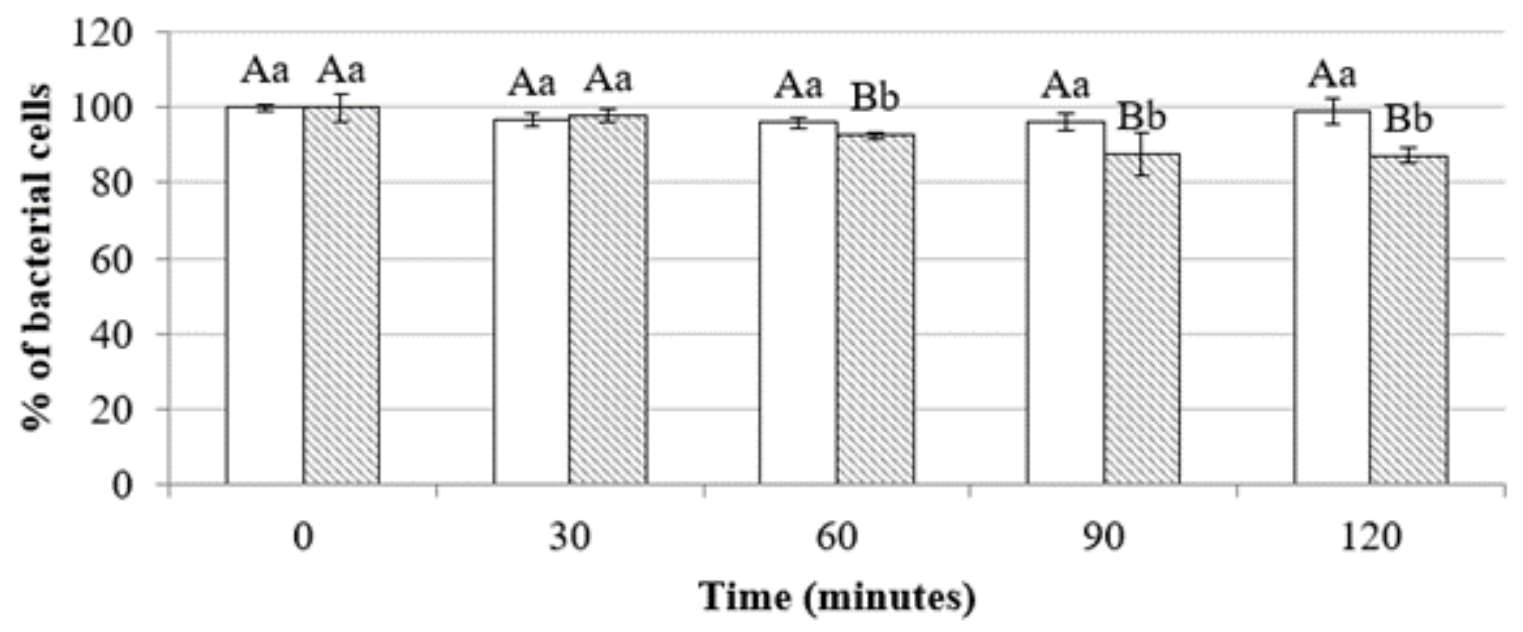


Figure 2

See manuscript for full figure caption.

A

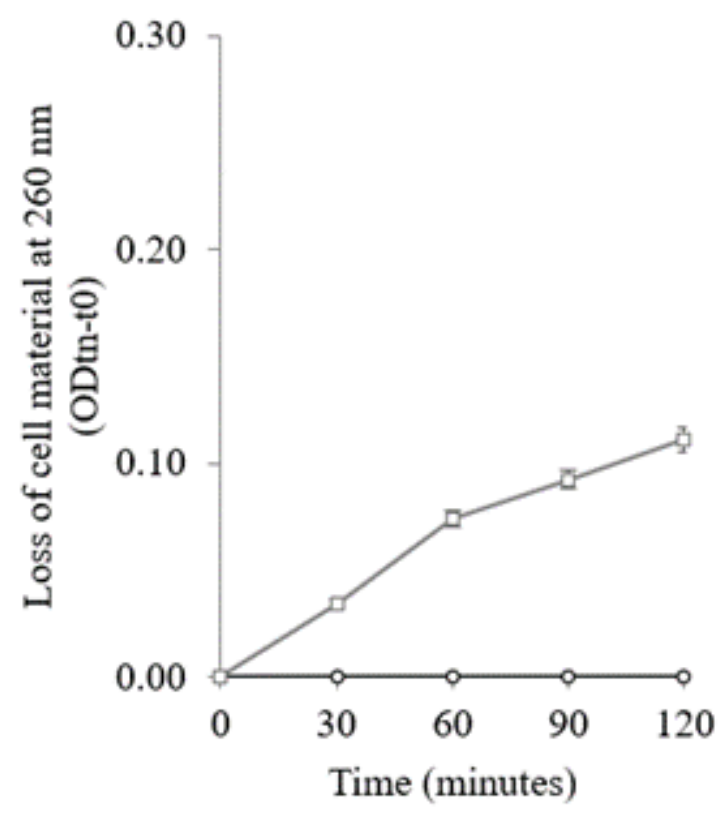

B

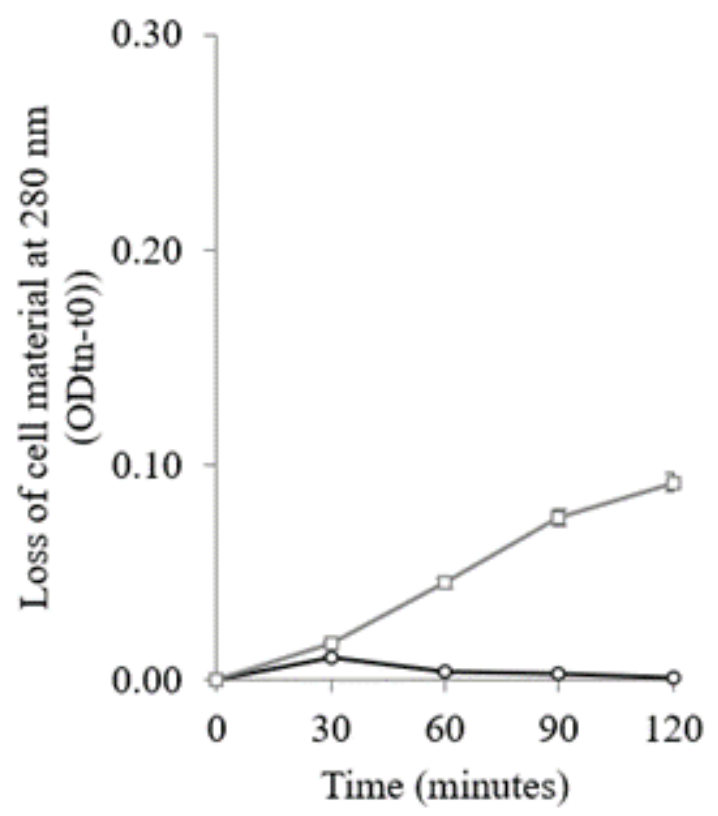

\section{Figure 3}

Absorbent material release to $260 \mathrm{~nm}(\mathrm{~A})$ and $280 \mathrm{~nm}(\mathrm{~B})$ in extracellular medium of S. Typhimurium cells untreated (circles) and treated (squares) with Lippia graveolens essential oil at MIC. Mean values of triplicate independent experiments and standard deviation are shown $(n=6)$.

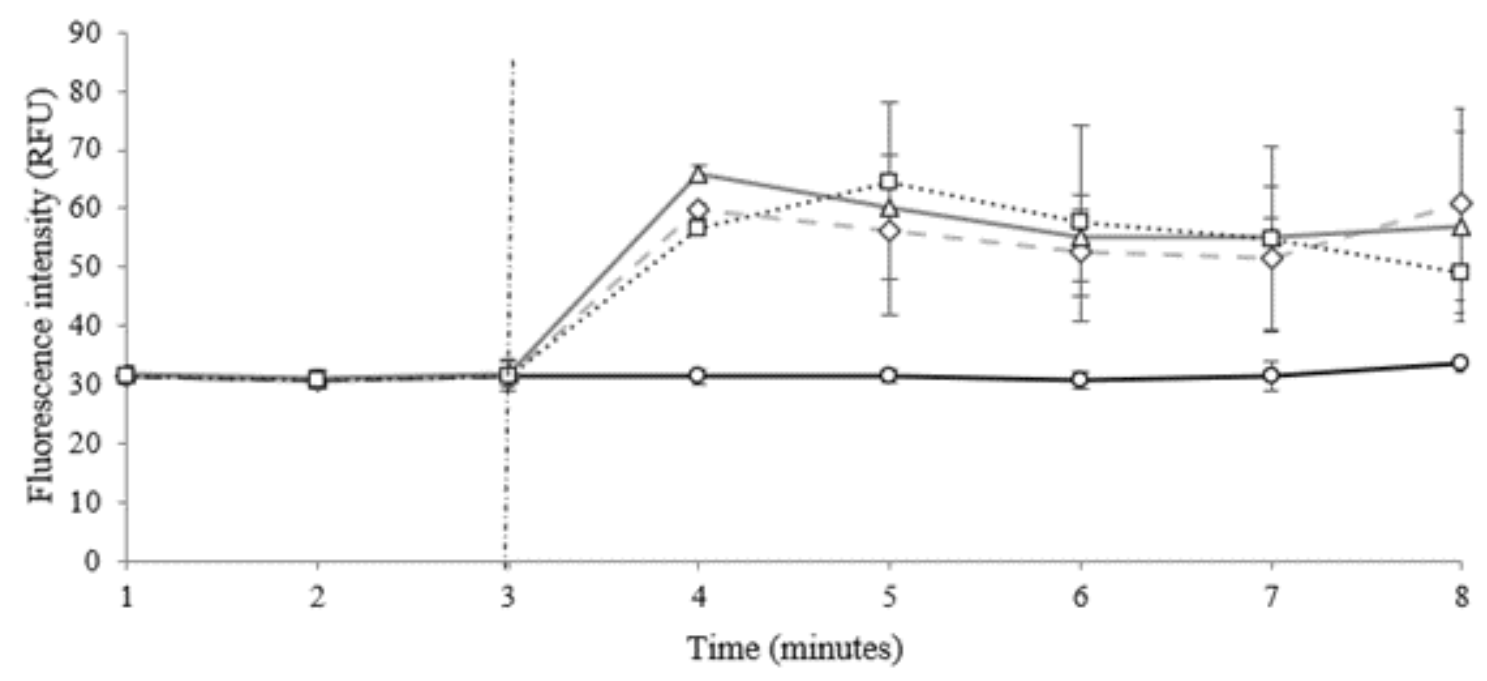

$\longrightarrow$ Control $-\diamond-$ Polymyxin B $\quad \triangle$ CTAB $\quad \cdots$ - $\quad$ - Lippiagraveolens

Figure 4 
Depolarization of the cytoplasmic membrane of cells of S. Typhimurium treated with Lippia graveolens essential oil at MIC (squares), with $30 \mathrm{mM} \mathrm{PMB}$ (diamond) and $4 \mathrm{mM}$ CTAB (triangle) monitored by fluorescence intensity change. Untreated cells used as control negative (circles). Mean values of triplicate independent experiments and standard deviation are shown $(n=6)$. The treatment was added after two minutes of equilibration (dashed line).

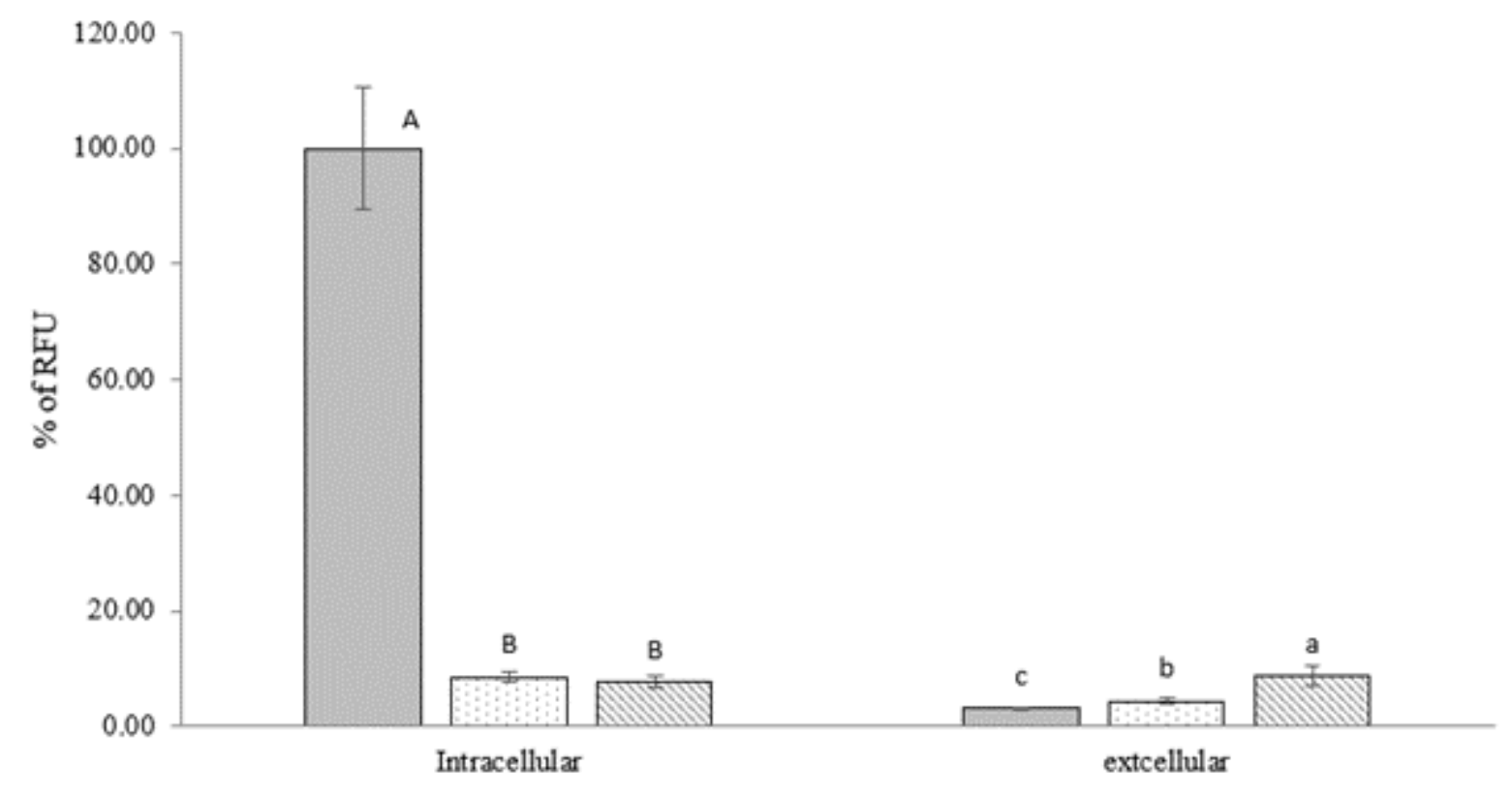

\section{Figure 5}

See manuscript for full figure caption. 

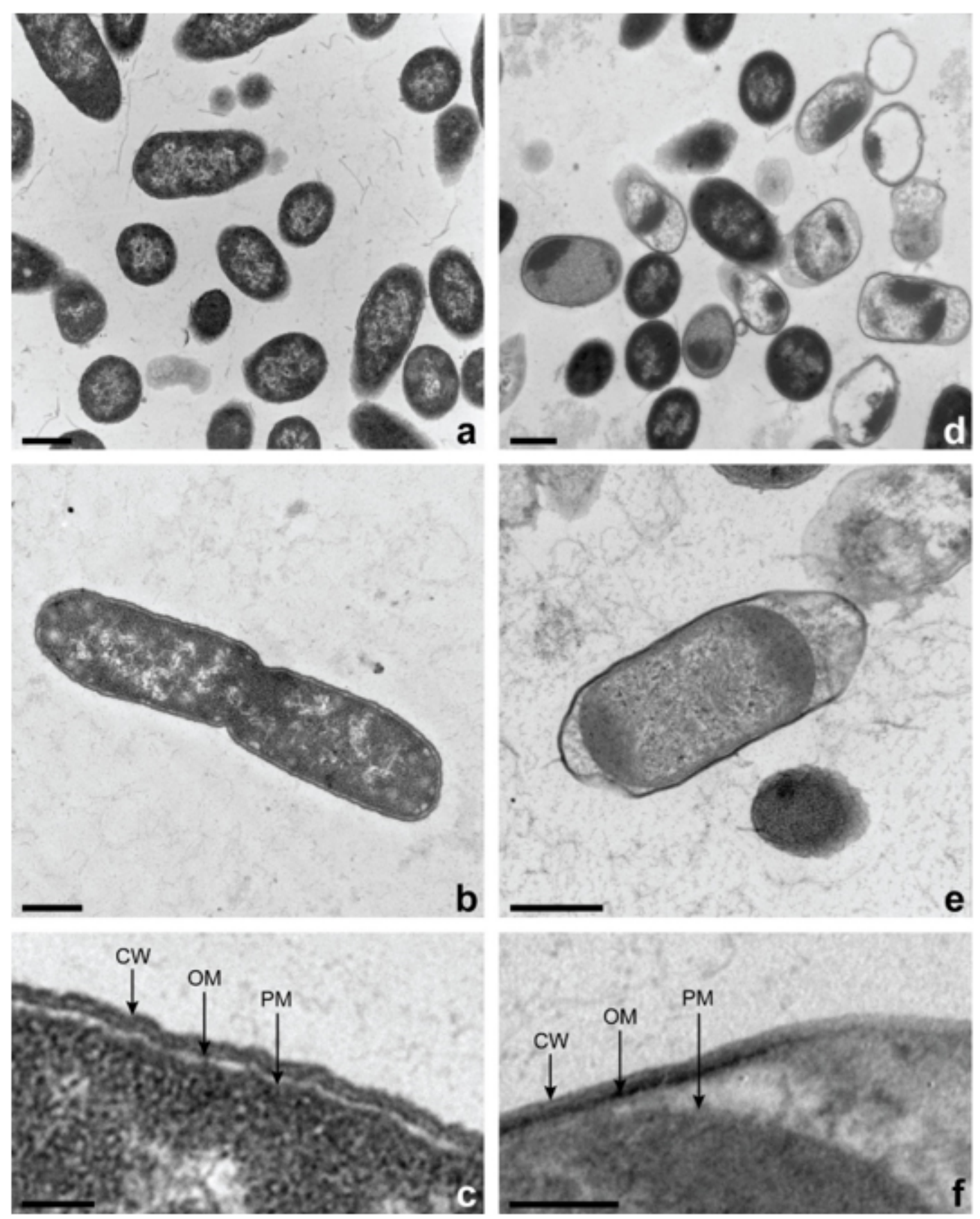

\section{Figure 6}

Transmission electron micrographs of S. Typhimurium cells stained. (a-b) control cells with $500 \mathrm{~nm}$ scale bar and (c) $100 \mathrm{~nm}$ scale bar. (d-e) S. Typhimurium cells treated with L. graveolens oil at the MIC with 500 $\mathrm{nm}$ scale bar and (f) $100 \mathrm{~nm}$ scale bar. OM: outer membrane; PL: peptidoglycan layer, PM: plasmic membrane.

\section{Supplementary Files}

This is a list of supplementary files associated with this preprint. Click to download. 
- GAannieBB2021.pdf 